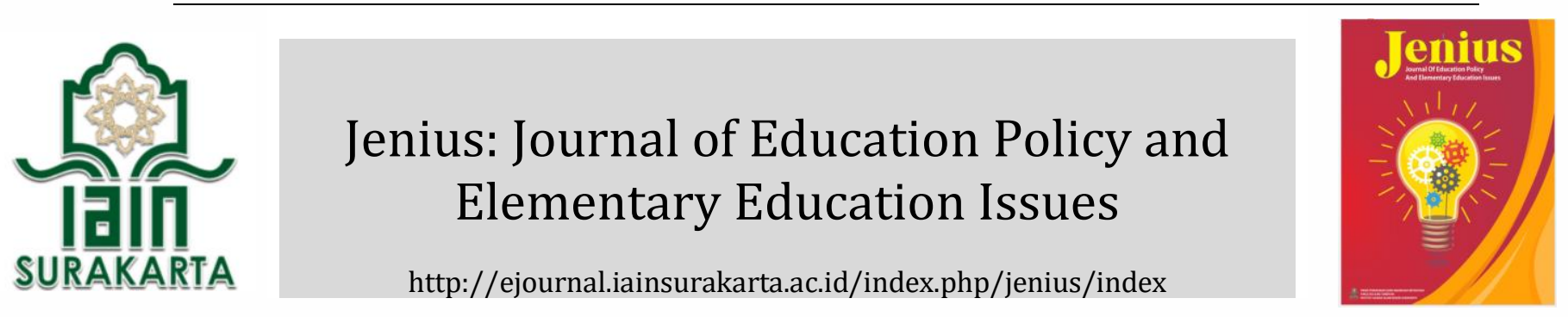

\section{Analisis Penerapan Nilai Karakter di Sekolah Dasar Selama Pandemi COVID-19}

\author{
Nikky Anisha 1*, Kustiarini ${ }^{2}$, Dita Purwinda Anggrella ${ }^{2}$
}

1,2 Pendidikan Guru Madrasah Ibtidaiyah, Fakultas Ilmu Tarbiyah, IAIN Surakarta, Indonesia

*Corresponding author: nikkyanisha@gmail.com

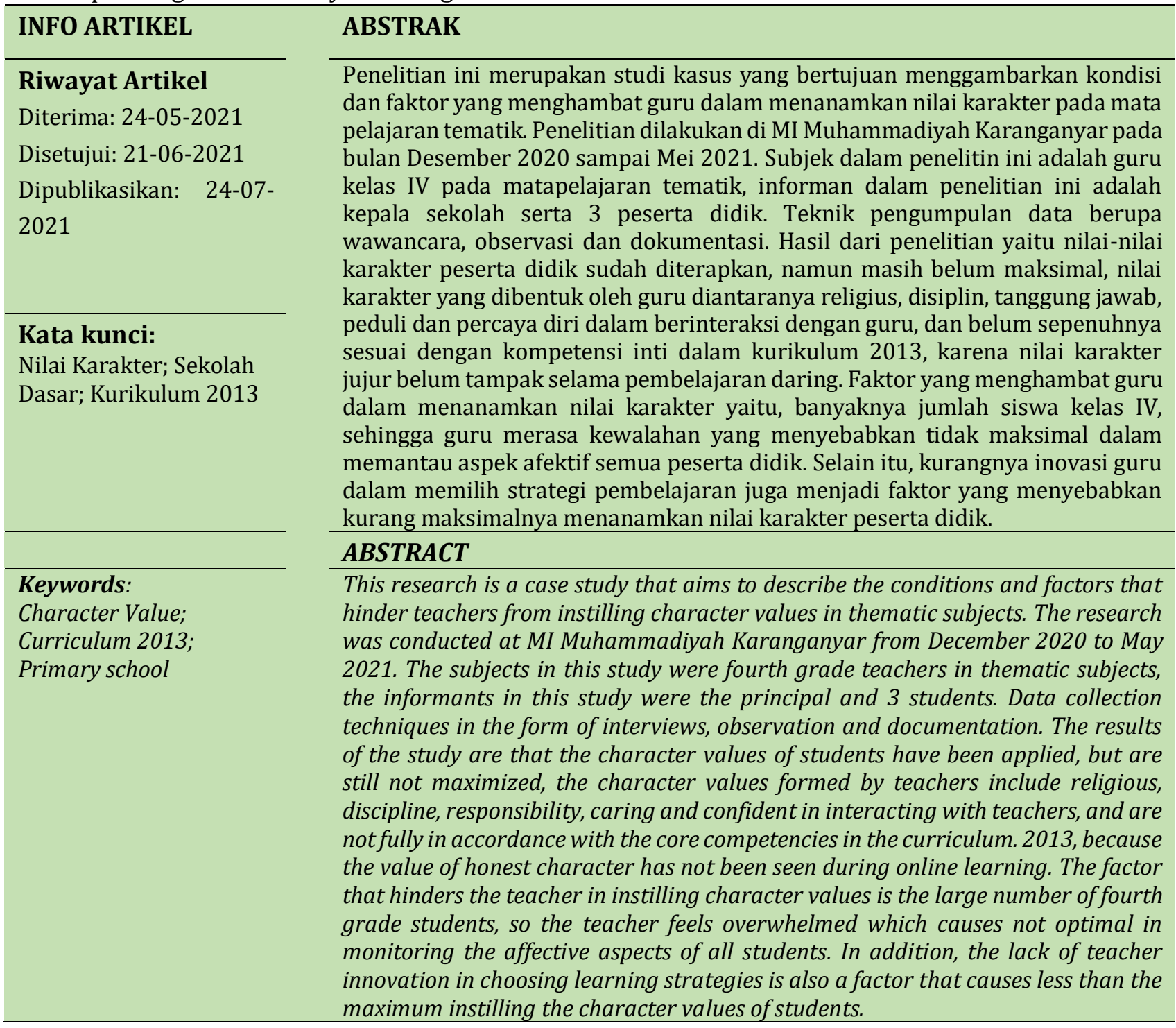




\section{PENDAHULUAN}

Krisis nilai-nilai karakter merupakan salah satu masalah yang sangat krusial yang dihadapi oleh bangsa saat ini. Hal ini tercermin dari karakter orang-orang yang berpendidikan bahkan tidak sedikit yang memiliki jabatan strategis di pemerintah atau masyarakat, krisis akan nilai-nilai karakter seperti korupsi (Arifin dan Irsan, 2019; Ismansyah, \& Sulistyo, 2010; Rahman, 2011; Setiadi, 2018) penyalahgunaan kekuasaan (Al Hafis, \& Yogia, 2017; Kaitu, 2020), dan tindakan kriminal (Laksana, 2015; Prayadi, 2020; Abdullah, 2019). Realita ini menunjukkan bahwa lembaga pendidikan belum berhasil menyiapkan lulusan yang memiliki komitmen dan bermoral tinggi. Hal ini menyebabkan pemerintah harus mengeluarkan kebijakan untuk membentuk karakter bangsa ini menjadi lebih baik melalui Kementerian Pendidikan dan Kebudayaan mengenai integrasi pendidikan karakter ke setiap matapelajaran yang dirumuskan dalam kurikulum 2013 (Permendikbud No 20 Tahun 2018).

Terintegrasinya pendidikan karakter pada kurikulum 2013 merupakan hal yang penting untuk menjadikan bangsa yang maju dan beradap. Hal ini sejalan dengan Penelitian Widisuseno (2018) menyatakan bahwa bangsa yang maju bukan karena memiliki Sumber Daya Alam (SDA) yang melimpah, melainkan bangsa yang memiliki karakter yang kuat, seperti kreatif, ulet, gigih, mandiri, kepedulian sesama, inovatif dan santun. Terintegrasinya nilai karakter ke dalam kurikulum 2013 dirumuskan pemerintah pada semua jenjang pendidikan. Menurut Arismantoro (2008), pembentukan karakter dimulai sejak lahir sampai umur 8 tahun, dan dapat berubah-ubah sesuai pengalaman hidupnya, sehingga pembentukan karater perlu ditanamkan sejak dini. Sekolah dasar merupakan usia (6 sampai 12 tahun) dimana anak mengalami perkembangan fisik dan motorik seperti watak emosional, intelektual, bahasa, perkembangan kepribadian, budi pekerti, dan moral yang bertumbuh dengan pesat (Kusrahmadi, 2007). Sehingga pendidikan dasar menjadi prioritas utama untuk menanamkan nilai-nilai karakter pada peserta didik. Menurut Permendikbud No 20 Tahun 2018 tentang penguatan pendidikan karakter (PPK) satuan pendidikan formal, menjelaskan pengembangan karakter bangsa terdiri dari nilai: religius, jujur, toleransi, disiplin kreatif, kerja keras, mandiri, demokratis, rasa ingin tahu, semangat kebangsaan, cinta tanah air, menghargai prestasi, bersahabat, cinta damai, gemar membaca, peduli lingkungan, peduli sosial, dan tanggung jawab- Nilai tersebut saling berkaitan dan perwujudan dari 5 nilai utama yaitu religiusitas, nasionalisme, kemandirian, gotong royong, dan integritas.

Namun, terintegrasinya nilai karakter ke dalam pembelajaran belum menjamin dapat membentuk karakter peserta didik menjadi lebih baik, karena masih saja ditemukan 
merosotnya nilai karakter dikalangan pelajar, seperti tawuran (Basri, 2015), curang dalam ujian (Kompas, 2021), bergesernya nilai budaya (Balya, Pratiwi, \& Prabudi, 2018; Kaparang, 2013). Hal ini membuktikan bahwa pendidikan karakter atau penanaman nilai karakter pada peserta didik masih belum optimal. Ditambah lagi sejak adanya pandemi Coronaviruses disease 2019 (COVID-19), penanaman nilai karakter menjadi tantangan tersendiri bagi guru (Nurgiansah, 2020).

Pandemi COVID-19 menyebabkan pemerintah harus mengeluarkan kebijakan untuk melakukan pembelajaran jarak jauh (Kemendikbud, 2013). Pembelajaran jarak jauh atau pembelajaran daring menyebabkan motivasi belajar peserta didik menurun dan lebih cenderung bermain game di smartphonenya, serta seringkali mengabaikan tugas dari guru (Robandi and Mudjiran, 2020). Berdasarkan penelitian Nafisah dan Zafi (2020) terdapat penurunan karakter peserta didik selama pandemi COVID-19. Berdasar masalah yang dijelaskan pada latar belakang, maka peneliti tertarik untuk menganalisis penanaman nilai karakter peserta didik pada pembelajaran selama masa pandemi COVID-19.

\section{METODE}

Penelitian ini merupakan studi kasus yang dianalisis secara deskriptif kualitatif. Penelitian dilakukan di MI Muhammadiyah Karanganyar pada bulan Desember 2020 sampai Mei 2021. Subjek dalam penelitian ini adalah guru kelas IV, dan informan yaitu kepala madrasah dan siswa (tiga siswa kelas IV). Teknik pengumpulan data berupa wawancara, observasi dan dokumentasi. Wawancara yang dilakukan dengan guru kelas IV, terkait penerapan nilai karakter, dan faktor yang menghambat dalam membentuk nilai karakter. Observasi yang digunakan dalam penelitian ini adalah observasi dengan mengikuti proses pembelajaran pada mata pelajaran tematik seacra daring. Observasi online yang menggunakan platform google classroom, dan zoom meeting. Observasi ini untuk memonitoring penerapan nilai karakter dan kendala penerapan nilai karakter. Pengumpulan data dengan dokumentasi melalui pengumpulan dokumen yang mendukung penelitian seperti RPP, presensi, dan tugas.

\section{HASIL DAN PEMBAHASAN}

Nilai karakter merupakan hal yang sangat krusial yang harus ditanamkan terutama di sekolah dalam matapelajaran tematik di kelas, sebagaimana yang dijelaskan dalam PPK bahwa untuk dapat mendidik karakter peserta didik salah satunya melalui pendekatan berbasis kelas dengan mengintegrasikan nilai karakter dalam proses pembelajaran secara tematik sesuai dengan isi kurikulum (Permendikbud No 20 Tahun 2018), harapannya dapat membentuk 
kepribadian peserta didik (Rawana et al., 2011) dan yang terpenting adalah nilai karakter tersebut dapat sampai, dipahami, tertanam, dan diharapkan menjadi perilaku permanen dalam setiap diri peserta didik. MI Muhammadiyah Karanganyar merupakan salah satu sekolah dasar yang selalu mengajarkan peserta didiknya akan nilai karakter yang baik.

Selama pandemi COVID-19, pembelajaran tematik dilaksanakan menggunakan platform google classroom, zoom meeting dan Whatsapp. Sebelum melaksanakan pembelajaran, guru sudah merancang RPP sebagai acuan dalam mengajar. Berdasarkan hasil dokumentasi, indikator nilai karakter tidak tercantum secara eksplisit, namun secara implisit tersirat dalam RPP. Hal ini terlihat berdasar hasil observasi dilapangan, hanya beberapa indikator yang tampak di terapkan oleh guru.

Berdasarkan hasil monitoring selama pembelajaran daring, terdapat 4 nilai karakter yang ditanamkan oleh guru, diantaranya:

1. Religius

Nilai ini terlihat seperti membaca Al-quran sebelum memulai pembelajaran, serta doa sebelum dan sesudah pembelajaran. Selain itu, guru juga mengajak siswa selalu bersyukur akan perbedaan budaya, pada pembelajaran dengan tema keragaman budaya yang dimiliki oleh Indonesia. Syam (2009) menyatakan peningkatan sikap religius seseorang diikuti dengan spiritual sosialnya akan mengembangkan sikap toleransi antar sesama.

2. Disiplin

Nilai ini terlihat saat guru mengajak siswa masuk google classroom dan zoom sesuai kesepakatan. Peserta didik mengikuti pebelajaran online tepat waktu, hal ini terlihat saat guru mengecek kehadiran peserta didik. Selain itu, peserta didik juga mengumpulkan tugas tepat waktu sesuai kesepakatan yang telah ditentukan guru.

3. Tanggung jawab

Nilai ini terlihat saat guru memberikan berbagai pemberian tugas harian. Peserta didik menyelesaikan tugas dalam waktu tertentu. Selain itu, sebelum pembelajaran dimulai, tanpa perintah dari guru, peserta didik sudah bersiap untuk berdoa bersama dengan dipimpin satu peserta didik yang memimpin doa. Hal ini menunjukkan peserta didik sudah memiliki tanggung jawab atas dirinya untuk selalu berdoa sebelum dan sesudah melakukan suatu kegiatan belajar, dan dapat mengerjakan tugas yang telah diberikan oleh guru.

4. Peduli dan percaya diri dalam berinteraksi dengan guru

Nilai ini terlihat ketika peserta didik bertanya kepada guru terkait materi yang belum dimengerti. Guru juga menyediakan platform google classroom apabila peserta didik masih 
merasa kurang paham terkait materi yang telah disampaikan. Tidak malu untuk bertanya terkait materi yang belum dimengerti sudah membentuk nilai percaya diri peserta didik. Kurang pahamnya peserta didik dalam pembelajaran kemungkinan dikarenakan metode yang digunakan guru kurang inovatif, yang menyebabkan peserta didik menjadi kurang paham terkait materi, pemahaman materi akan lebih mudah ditangkap apabila ditunjang dengan model pembelajaran saintifik (Rohmawati, Sihkabuden, \& Susilaningsih, 2019), media pembelajaran (Maulidina \& Bhakti, 2020; Suasty \& Hadi, 2020) dan lingkungan yang lebih kontekstual (Arta, Hendrayana, \& Ihsanudin, 2020).

Apabila ditelusuri berdasar analisis kurikulum 2013 kompetensi Inti (KI) 1 dan KI 2 kelas IV, nilai karakter yang harus dicapai oleh peserta didik adalah dari aspek spiritual berupa nilai religius (menerima, menjalankan, dan menghargai ajaran agamanya), dan dari aspek sikap sosial adalah nilai karakter jujur, disiplin, tanggungjawab, peduli dan percaya diri dalam berinteraksi dengan keluarga, teman, guru dan tetangganya (Permendikbud, 2018). Beberapa nilai karakter sudah terlihat dalam proses pembelajaran. Sedangkan aspek jujur, menjadi permasalahan baru yang harus ditangani oleh guru dalam proses pembelajaran, dikarenakan metode yang digunakan guru adalah ceramah dan diskusi sehingga ditakutkan akan membuat peserta didik menjadi bosan dalam kelas online, ditambah jumlah siswa yang begitu banyak mengikuti pembelajaran daring menyebabkan guru kewalahan dan tidak bisa memperhatikan semua gerak-gerik dari peserta didik, sehingga beberapa peserta didik berada diluar pengawasan guru. Keterbatasan dalam penelitian ini kurang menelusuri lebih dalam terkait indikator kejujuran dalam nilai karakter dalam proses pembelajaran. Nilai karakter dapat dipantau melalui kehadiran peserta didik dengan menyelakan video conference mulai awal sampai akhir, dan nilai karakter jujur juga dapat diketahui dalam pengerjaan tugas dan ujian, namun keterbatasann dalam penelitian ini adalah kurang menggali lebih dalam terkait nilai tugas dan ujian, serta kejujuran peserta didik dalam mengerjakan ujian.

Selain mendidik peserta didik dengan nilai-nilai karakter, guru juga berperan sebagai motivator dan inspirator. Terlihat guru selalu memberikan motivasi pada peserta didik seperti memberikan semangat kepada siswa, menasihati agar lebih giat belajar dirumah dan menyelipkan nilai karakter religius melalui kegiatan berdoa sebelum dan sesudah pembelajaran dimulai. Selain sebagai motivator, guru juga berperan sebagai inspirator bagi peserta didiknya, hal ini terlihat ketika pembelajaran, guru memberikan contoh atau teladan yang baik seperti menginspirasi siswa agar belajar dengan giat agar tercapai cita-citanya, datang tepat waktu, dan membaca Al-quran sebelum pembelajaran. Hal ini sejalan dengan 
pendapat Walgito (2004) bahwa pembentukan perilaku sampai menjadi karakter akan terjadi karena adanya teladan atau model yang ditiru, dan guru merupakan role model bagi peserta didiknya.

Selama monitoring proses pembelajaran daring, guru terlalu fokus dalam menyelesaikan tema materi pembelajaran, karena beradasar wawancara, guru merasa kesulitan dalam membentuk karakter siswa saat pembelajaran daring, sehingga hanya terlihat empat nilai karakter saja yang ditanamkan oleh guru. Berdasarkan hasil observasi dan dokumentasi RPP, guru kurang inovatif dalam memilih strategi pembelajaran, dimana metode yang digunakan berupa ceramah dan tanya jawab, sehingga nilai-nilai karakter yang ditanamkan kurang optimal dan hanya empat nilai karakter yang bisa ditanamkan guru. Hal ini tidak sejalan menurut penelitian Anggraini \& Kusniarti (2016), dimana seorang guru harus kreatif dalam implementasi pembelajaran dan mampu mengasah berbagai nilai-nilai karakter dalam pembelajaran. Seperti penelitian Zafirah et al (2018), mampu menerapkan pembelajaran yang kreatif dengan memanfaatkan media pembelajaran seperti congklak (permainan tradisional) dalam pembelajaran tematik, dan hasilnya mampu menanamkan sembilan nilai karakter yaitu jujur, disiplin, kerja keras, kreatif, rasa ingin tahu, mandiri, komunikatif, tanggung jawab, dan menghargai prestasi.

Hasil penelitian Sadia, Arnyanan, \& Muderawan (2013) menjelaskan bahwa pembentukan karakter dapat dikembangkan dengan memilih model pembelajaran saintifik seperti inkuiri, problem based learning, kooperatif, sains-teknologi-masyarakat (STM), problem solving, siklus belajar (Learning Cycle Model), pembelajran berbassis proyek (Project Based Learning) dan kontekstual (Maryati \& Priatna, 2017; Sadia, Arnyanan, \& Muderawan, 2013), kearifan lokal (Ramdani, 2018; Khusniati, 2014), dan model pembelajaran search, solve, create, and share (Assidiqi, 2015), selain itu guru juga dapat mengembangkan pembentukan karakter melalui model asesmen, dan pemilihan materi (Sadia, Arnyanan, \& Muderawan, 2013). Penelitian Sadia, Arnyanan, \& Muderawan (2013) dalam mengembangkan nilai karakter dengan berbagai model pembelajaran saintifik dapat membentuk nilai karakter seperti rasa hormat terhadap diri sendiri dan orang lain, tanggung jawab, kejujuran, keterbukaan, toleransi, membantu dengan tulus, disiplin-diri, kerjasama, nilai-nilai demokrasi, kehati-hatian, keteguhan hati, empati, percaya diri, patuh pada aturan/norma social, religius, mandiri, berpikir logis, kritis, kreatif, dan inovatif, menghargai keberagaman, kerja keras, dan peduli sosial dan lingkungan.

Berdasar hasil penelitian terdahulu, terbukti bahwa penanaman nilai karakter dapat 
dilakukan secara inovataif dengan berbagai cara. Hal ini didukung berdasar penelitian Leslie \& Grier (2012) bahwasanya penanaman nilai karakter dapat berhasil apabila dilakukan melalui berbagai pendekatan, karena jika hanya bertumpu pada salah satu strategi, maka strategi tersebut sudah tidak memadai dalam penanaman nilai karakter (Lynn, Revell \& James, 2007).

Beradasarkan hasil wawancara menunjukkan guru merasa kesulitan menerapkan nilainilai karakter selama pembelajaran daring karena tidak dapat memantau secara langsung dengan jumlah peserta didik yang banyak di kelas, sehingga guru merasa kewalahan untuk menilai aspek afektif peserta didik, ditakutkan ketika peserta didik merasa bosan ketika pembelajaran daring, mereka akan mematikan video conference-nya. Nurgiansyah \& Sukmawali (2020) menjelaskan bahwasanya ketika peserta didik merasa bosan dalam proses pembelajaran daring, maka peserta didik akan mematikan video conference-nya, dan hanya log in untuk join ke dalam kelas online. Jika peristiwa ini terjadi, maka kebohongan yang dilakukan peserta didik ini berdampak pada aspek nilai karakter kejujuran. Keterbatasan dalam penelitian ini adalah, kurang telitinya guru maupun peneliti dalam memantau apakah semua peserta didik mengikuti proses pembelajaran daring mulai awal sampai akhir.

Faktor penghambat yang lain dalam proses pembelajaran dalam menanamkan nilai karakter adalah, pembelajaran online tidak leluasa seperti pembelajaran luring, sehingga guru tidak dapat menanamkan nilai karakter yang bervariatif. Guru hanya bisa mempercayakan selebihnya penanaman nilai karakter kepada orang tua dan lingkungan keluarga selama pandemi COVID-19 ini. Prabowo, Fakhruddin, \& Rohman (2020) dalam penelitiannya menjelaskan bahwa selama masa pandemi, orang tua memiliki peran yang lebih besar untuk membentuk karakter anak, namun akibat pembelajaran online, menjadi tantangan bagi orang tua dalam membimbing dan mengawasi anak, pasalnya anak lebih cenderung bermain gadget yang terkadang disalahgunakan. Orang tua memiliki peran dalam mendidik karakter anaknya dalam bentuk motivator, fasilitator, pendamping dan pengawas, pendidik atau edukator serta sebagai figure bagi anaknya.

Berdasarkan hasil penelitian menunjukkan strategi penerapan nilai-nilai karakter peserta didik sudah diterapkan, namun masih belum maksimal. Baginda (2018) dalam penelitiannya merekomendasikan, berhasilnya penanaman nilai karaker yaitu dengan menuliskan target yang akan dicapai di setiap matapelajaran, sehingga ketika proses pembelajaran, guru tidak hanya fokus pada aspek kognitif saja. 


\section{KESIMPULAN DAN SARAN}

\section{Simpulan}

Nilai karakter yang diterapkan oleh guru sudah sesuai dengan KI 1 dan KI 2 yang ada dalam kurikulum 2013, terkait penilaian sikap religius dan sosial, namun penerapannya kurang maksimal. Indikator yang ditanamkan oleh guru dalam mata pelajaran tematik adalah yaitu disiplin, tanggung jawab, religius. Sedangkan dalam KI 1 dan KI 2 nilai karakter yang harus dicapai oleh peserta didik adalah disiplin, tanggung jawab, religius, jujur, peduli dan percaya diri dalam berinteraksi dengan guru. Aspek jujur masih belum nampak saat proses pembelajaran berlangsung. Faktor penghambat dalam menanamkan nilai karaktaer dalam proses pembelajran adalah, guru merasa kewalahan memantau semua peserta didik yang megikuti kelas online karena jumlah kelas IV yang terlalu besar, sehingga guru tidak dapat memantau dan menilai aspek afektif seluruh sisiwa, selain itu kurangnya inovatifnya guru dalam menerapkan pembelajaran daring juga menjadi faktor penerapan nilai karakter menajadi terbatas.

\section{DAFTAR RUJUKAN}

Abdullah, R. H. (2019). Tinjauan viktimologis terhadap tindak pidana perdagangan orang (human trafficking). Jurnal Yustika: Media Hukum dan Keadilan, 22(01), 55-63.

Al Hafis, R. I., \& Yogia, M. A. (2017). Abuse of power: Tinjauan terhadap penyalahgunaan kekuasaan oleh pejabat publik di Indonesia. Publika: Jurnal Ilmu Administrasi Publik, 3(1), 80-88.

Anggraini, P., \& Kusniarti, T. (2016). The implementation of character education modelbased on empowerment theatre for primary school students. Journal of Education and Practice, 7(1), 26-29.

Arifin, Z., \& Irsan, I. (2019). Korupsi perizinan dalam perjalanan otonomi daerah di indonesia. Lex Librum: Jurnal Ilmu Hukum, 5(2), 887-896.

Arismantoro. (2008). Tinjauan berbagai aspek character building bagaimana mendidik anak berkarakter. Yogyakarta: Tiara Wacana.

Arta, A. Y., Hendrayana, A., \& Ihsanudin, I. (2020). Pengembangan pembelajaran daring matematika berbasis pendekatan kontekstual siswa SMP. Wilangan: Jurnal Inovasi dan Riset Pendidikan Matematika, 1(4), 353-366.

Assidiqi, H. (2015). Membentuk karakter peserta didik melalui model pembelajaran search, solve, create, and share. Math Didactic: Jurnal Pendidikan Matematika, 1(1), 45-55. doi: 10.33654/math.v1i1.94.

Baginda, M. (2018). Nilai-nilai pendidikan berbasis karakter pada pendidikan dasar dan menengah. Jurnal Ilmiah Iqra', 10(2), 1-12. doi: 10.30984/jii.v10i2.593. 
Balya, T., Pratiwi, S., \& Prabudi, R. (2018). Literasi media digital pada penggunaan gadget (studi deskriptif penggunaan gadget pada siswa SMK broadcasting bina creative medan yang berdampak pada pergeseran nilai kearifan lokal). Jurnal Simbolika: Research and Learning in Communication Study, 4(2), 173-187. doi: 10.31289/simbollika.v4i2.1898.

Basri, A. S. H. (2015). Fenomena tawuran antar pelajar dan intervensinya. Hisbah: Jurnal Bimbingan Konseling dan Dakwah Islam, 12(1), 1-25. doi: 10.14421/hisbah.2015.121-06.

Ismansyah, I., \& Sulistyo, P. A. (2010). Permasalahan korupsi, kolusi, dan nepotisme di daerah serta strategi penanggulangannya. Jurnal Demokrasi, 9(1), 43-60.

Kaitu, K. K. (2020). Tinjauan yuridis terhadap penyalahgunaan wewenang pejabat administrasi negara menurut hukum administrasi negara (Doctoral Dissertation, Universitas Sintuwu Maroso).

Kaparang, O. M. (2013). Analisa gaya hidup remaja dalam mengimitasi budaya pop Korea melalui televisi. Acta Diurna Komunikasi, 2(2).

Keputusan Menteri Pendidikan dan Kebudayaan No.4 Tahun 2020. Pelaksanaan kebijakan pendidikan dalam masa darurat penyebaran coronavirus disease (COVID-19). Surat Edaran dari Kementerian RI, 2020. Retrieved from https://pusdiklat.kemdikbud.go.id/surat-edaran-mendikbud-no-4-tahun-2020tentang-pelaksanaan-kebijakan-pendidikan-dalam-masa-darurat-penyebaran-coronavirus-disease-covid-1-9/

Khusniati, M. (2014). Model pembelajaran sains berbasis kearifan lokal dalam menumbuhkan karakter konservasi. Indonesian Journal of Conservation,3(1). doi: 10.15294/ijc.v3i1.3091.

Kompas. (2021, Mei). Terbongkar, soal ujian akhir smp di jember bocor, bermula siswa tak mau kumpulkan HP, 48 murid ujian ulang. Bagus supriadi. Retrived from https://regional.kompas.com/read/2021/05/07/163309478/terbongkar-soal-ujianakhir-smp-di-jember-bocor-bermula-siswa-tak-mau?nomgid=1\&page=all.

Kusrahmadi, S. D. (2007). Pentingnya pendidikan moral bagi anak sekolah dasar. Dinamika Pendidikan, 118-129.

Laksana, L. S. K. (2015). Tinjauan kriminologi terhadap penyalahgunaan senjata api oleh anggota kepolisian republik Indonesia. Universitas Hasannudin, Makassar.

Leslie, K. \& Grier. (2012). Character, social- emotional, and academic outcomes among underachieving elementary school students. Journal of Education for Students Placed at Risk (JESPAR), 17(3), 201-216. doi: 10.1080/10824669.2012.672834

Lynn, Revell \& James, Arthur. (2007). Character education in schools and the education of $\begin{array}{llll}\text { teachers. Journal of Moral } & \text { Education, }\end{array}$ doi.org/10.1080/03057240701194738

Maryati, I., \& Priatna, N. (2017). Integrasi nilai-nilai karakter matematika melalui pembelajaran kontekstual. Mosharafa: Jurnal Pendidikan Matematika, 6(3), 333-344.

Maulidina, S., \& Bhakti, Y. B. (2020). Pengaruh media pembelajaran online dalam pemahaman E-ISSN: 2775-3182 51 
dan minat belajar siswa pada konsep pelajaran fisika. ORBITA: Jurnal Kajian, Inovasi Dan Aplikasi Pendidikan Fisika, 6(2), 248-251.

Murniyetti, Engkizar, \& Anwar, F. (2016). Pola pelaksanaan pendidikan karakter terhadap siswa sekolah dasar. Jurnal Pendidikan Karakter, 6(2), 157-166.

Nafisah, F. T. and Zafi, A. A. (2020). Model pendidikan karakter berbasis keluarga perspektif islam di tengah pendemi covid-19. Ta'allum: Jurnal Pendidikan Islam, 8(1), 1-20. doi: 10.21274/taalum.2020.8.1.1-20

Nurgiansah, T. H., Sukmawali. (2020). Tantangan guru pendidikan kewarganegaraan di masa adaptasi kebiasaan baru. Jurpis: Jurnal Pendidikan Ilmu Sosial, 17(2), 139-149.

Peraturan Meneteri Pendidikan Dan Kebudayaan RI, No 37 Tahun 2018. Perubahan atas peraturan menteri pendidikan dan kebudayaan no 24 tahun 2016 tentang kompetensi inti dan kometensi dasar pelajaran pada kurikulum 2013 pada pendidikan dasar dan pendidikan menengah. Menteri Pendidikan dan Kebudayaan RI, 2018. Retrieved from https://jdih.kemdikbud.go.id/arsip/Permendikbud\%20Nomor\%2037\%20Tahun\%202 018.pdf.

Peraturan Menteri Pendidikan dan Kebudayaan No.20 Tahun 2018. Penguatan pendidikan karakter pada satuan pendidikan formal. Menteri Pendidikan dan Kebudayaan RI, 2018. Retrieved from https://jdih.kemdikbud.go.id/arsip/Permendikbud_Tahun2018_Nomor20.pdf.

Prabowo, S. H., Fakhruddin, A., \& Rohman, M. (2020). Peran orang tua dalam pembentukan karakter anak di masa pandemi COVID-19 perspektif pendidikan islam. Al-Tadzkiyyah: Jurnal Pendidikan Islam, 11(2), 191-207. doi: 10.24042/atjpi.v11i2.7806.

Prayadi, J. S. (2010). Tinjauan viktimologis terhadap warga negara asing (WNA) yang menjadi korban kejahatan (studi di wilayah hukum polres lombok tengah) (Doctoral dissertation, Universitas Mataram).

Rahman, F. (2011). Korupsi di tingkat desa. Governance, 2(1), 13-24.

Ramdani, E. (2018). Model pembelajaran kontekstual berbasis kearifan lokal sebagai penguatan pendidikan karakter.JUPIIS: Jurnal Pendidikan IImu-IImu Sosial,10(1), 1-10. doi: 10.24114/jupiis.v10i1.8264.g9053.

Rawana, J. R., Franks, J. L., Brownlee, K., Rawana, E. P., \& Neckoway, R. (2011). The application of a strength-based approach of students' behaviours to the development of a character education curriculum for elementary and secondary schools. The Journal of Educational Thought (JET)/Revue de la PenséeEducative, 45(16), 127- 144.

Robandi, D. and Mudjiran, M. (2020). Dampak pembelajaran dari masa pandemi COVID-19 terhadap motivasi belajar siswa SMP di Kota Bukittinggi. Jurnal Pendidikan Tambusai, 4(3), 3498-3502. doi: 10.31004/jptam.v4i3.878.

Rohmawati, S., Sihkabuden, S., \& Susilaningsih, S. (2019). Penerapan pendekatan saintifik pada mata pelajaran IPA di MTs putri nurul masyithoh Lumajang. Jurnal Kajian Teknologi Pendidikan, 1(3), 205-212. 
Sadia, W. Arnyanan, I.B.Putu., Muderawan I.W. (2013). Model pendidikan karakter terintegrasi pembelajaran sains. JPI Uurnal Pendidikan Indonesia),2(2). doi: 10.23887/jpiundiksha.v2i2.2165.

Setiadi, W. (2018). Korupsi di indonesia penyebab, hambatan, solusi dan regulasi. Jurnal Legislasi Indonesia, 15(3), 249-262.

Suasty, F., \& Hadi, A. A. (2020). Penggunan media pembelajaran video untuk solusi penurunan pemahaman materi pembelajaran ketika belajar online akibat pandemic COVID19. Milenial: Journal for Teachers and Learning, 1(1), 12-16.

Syam, Nur. (2009). Tantangan multikulturalisme Indonesia: Dari radikalisme menuju kebangsaan. Yogyakarta: Kanisius.

Walgito, Bimo. (2004). Pengantar psikologi umum. Yogyakarta: Fakultas Psikologi UGM.

Widisuseno, I. (2018). Pola budaya pembentukan karakter dalam sistem pendidikan di Jepang. Kiryoku, 2(4), 221-230. doi: 10.14710/kiryoku.v2i4.48-57.

Zafirah, A., Agusti, F. A., Engkizar, E., Anwar, F., Alvi, A. F., \& Ernawati, E. (2018). Penanaman nilai-nilai karakter terhadap peserta didik melalui permainan congkak sebagai media pembelajaran. Jurnal Pendidikan Karakter, 8(1), 95-104. doi: 10.21831/jpk.v8i1.21678. 